\title{
Neoadjuvant Chemotherapy in Malignant Pleural Mesothelioma
}

\author{
Giulia Pasello and Adolfo Favaretto
}

Additional information is available at the end of the chapter

http://dx.doi.org/10.5772/47880

\section{Introduction}

Malignant pleural mesothelioma (MPM) is a rare and aggressive tumour with a poor prognosis, directly related to chronic inhalation of asbestos fibres. Despite the extraction, import and marketing of the mineral were banned in most of the industrialized nations, the epidemiologic data foresee a sharp rise of MPM incidence and mortality in the next fifteen years because of the long lag time (even 40 years) from exposure to clinical evidence (Marinaccio et al., 2007).

Malignant mesothelioma is usually diagnosed in the advanced stages and single-modality treatment generally did not achieve higher results than supportive care. MPM shows high refractoriety to systemic treatment, and the response rate in previous series was about $10 \%$ $20 \%$ with anthracyclines, antimetabolites, or single agents platinum analogs.

Doublet chemotherapy showed similar results, even though some combinations yielded higher response rates than single agents. Responses are of short duration and complete responses are rarely observed. Currently available chemotherapy regimens achieved a response rate of $30-40 \%$ with rare complete responses, a median progression free and overall survival of approximately 6 and 12 months respectively (van Meerbeeck et al., 2005; Vogelzang et al., 2003).

With regard to local treatments, radiotherapy to the entire hemithorax may cause lifethreatening pulmonary toxicity when the lung is not removed.

Extrapleural pneumonectomy (EPP), a surgical procedure introduced in the seventies which implies en bloc resection of the parietal pleurae, lung, ipsilateral pericardium and hemidiaphragm, did not improve the incidence of local and distant recurrences and that was the reason for some centres to perform combined treatments. 
Multimodality therapies adopting a combination of surgical resection and adjuvant treatments (chemotherapy, radiotherapy or both) seem to be a better therapeutic option in selected patients (Sugarbaker et al., 1999); the successful results with neoadjuvant chemotherapy in the management of stage III Non-Small Cell Lung Cancer (Rosell et al., 1994) paved the way to several groups for applying this strategy in malignant mesothelioma.

Despite the improvement in diagnosis and treatment, the optimal therapy for mesothelioma patients is highly controversial and the role of surgery and trimodality treatment is under debate. There is no consensus about the benefits of neoadjuvant chemotherapy and about the more effective chemotherapy regimen, despite several clinical trials in this setting were performed.

\section{Rationale for neoadjuvant treatment in malignant pleural mesothelioma}

Treatment failure after surgery of malignant mesothelioma occurs frequently; in the attempt of reducing the incidence of local recurrences after extrapleural pneumonectomy, a multimodality approach with surgery followed by adjuvant radiotherapy was explored.

Extrapleural pneumonectomy allows higher doses of radiotherapy to the whole hemithorax by avoiding pulmonary toxicity and the results of this approach is a significant reduction of loco-regional relapses (Rusch et al., 2001).

The issue of extrathoracic metastasis represent a major challenge in the management of the disease because of the impact on overall survival (Rice et al., 2007)

Once a chemotherapy regimen showes activity in malignant pleural mesothelioma, the subsequent step is the addition of such treatment to surgery and radiotherapy to improve the systemic control of the disease.

The success with surgical resection after neoadjuvant chemotherapy in stage IIIA non-small cell lung cancer (Rosell et al., 1994) has been the impetus for several groups to apply this strategy in malignant mesothelioma aiming at reducing the incidence of distant relapse after surgery.

\subsection{Neoadjuvant chemotherapy in non-small cell lung cancer}

Until the nineties, local treatments such as surgery or radiotherapy were used alone to treat stage IIIA non-small cell lung cancer (locally invasive primary tumors or tumors associated with involvement of ipsilateral mediastinal or subcarineal lymphnodes). Five-years survival of non-small cell lung cancer patients is highly affected by stage of disease and lymphnodes involvement, and new approaches to improve overall survival has been investigated. The administration of systemic therapy before local treatment is generally referred to as induction or neoadjuvant therapy, and aims to prevent systemic spread of disease, to fight back micrometastasis and to reduce tumor size. 
In 1994, two randomized clinical trials compared the combination of preoperative chemotherapy and surgery to surgery alone (Rosell et al., 1994; Roth et al., 1994). Median survival time, in two trials respectively, were 26 and 64 months in patients treated with platinum-based chemotherapy followed by surgery compared to 8 and 11 months, respectively, in the group who underwent to surgery alone. The effectiveness of such approach was confirmed in a systematic review and meta-analysis where data from 7 randomized clinical trials were available; the authors reported a $18 \%$ relative reduction in the risk of death, a significant increase of overall survival and an absolute benefit of $6 \%$ at five years with the use of induction chemotherapy (Burdett et al., 2006, 2007). Subsequently, Song W. and colleagues, published an updated metanalysis with data from 13 studies, included 6 new randomized clinical trials; they reported a significant benefit in terms of overall survival in non-small lung cancer patients treated with chemotherapy followed by surgery compared to surgery alone, and the results were confirmed in the subgroup analysis where only stage III NSCLC patients were evaluated (Song et al., 2010).

\subsection{Path to neoadjuvant chemotherapy in malignant pleural mesothelioma}

The addition of systemic treatment to surgery and radiotherapy aims at reducing metastatic disease, even though the optimal sequence of the three is still unclear.

A major experience in surgical management of malignant mesothelioma was conducted by Sugarbaker et al. who tested the efficacy of extrapleural pneumonectomy followed by adjuvant chemotherapy and radiotherapy in 183 patients.

Chemotherapy regimen changed during study time window; doxorubicin and cyclophosphamide with or without cisplatin was administered in the first period, followed by carboplatin plus paclitaxel to later patients.

In their experience, patients with microscopic negative resection margins, epithelial histotype and negative lymphnodes, had a better long-term survival ( 2 and 5 year survival: 68 and $46 \%$, respectively; median 51 months) (Sugarbaker et al., 1999)

Patients with non-epithelial histology and extrapleural nodal involvement had worse survival and that underlines the need for a careful selection of patients undergoing a multimodality approach. A number of other studies were published with different regimens of adjuvant chemotherapy with a median overall survival of 13 to 23.9 months. Perioperative mortality in patients treated with adjuvant chemoradiotherapy ranged from 0 to $11 \%$ (Cao et al.,2010).

The difficult deliver of both postoperative chemotherapy and radiotherapy in most patients induced many groups to explore a trimodality approach based on preoperative chemotherapy, surgery and postoperative radiotherapy in the attempt of improving compliance.

Furthermore, as well as in non-small cell lung cancer, neoadjuvant chemotherapy could maximize cytoreduction and increase the proportion of patients able to complete the entire trimodality treatment. 


\section{Chemotherapy regimens in the neoadjuvant setting of malignant pleural mesothelioma}

Recently the use of neoadjuvant chemotherapy has been reported in 7 prospective and 3 retrospective published studies, with median overall survival ranging from 23 to 33 months in patients who completed the trimodality treatement (Table 1, 2). Preliminary data are available from other clinical trials, and some studies are still ongoing.

\begin{tabular}{|c|c|c|c|c|c|}
\hline Reference & $\begin{array}{c}\text { Weder et al., } \\
2004\end{array}$ & $\begin{array}{l}\text { Weder et al., } \\
2007\end{array}$ & Rea et al., 2007 & $\begin{array}{l}\text { Flores et al., } \\
2006\end{array}$ & Opitz et al., 2006 \\
\hline $\mathrm{N}^{\circ} \mathrm{pts}$ & 19 & 61 & 21 & 21 & 63 \\
\hline Study type & Prospective & Prospective & Prospective & Prospective & Retrospective \\
\hline CT & $\begin{array}{c}\text { C-DDP } 80 \\
\mathrm{mg} / \mathrm{m}^{2} \mathrm{~d} 1+\mathrm{G} \\
1000 \mathrm{mg} / \mathrm{m}^{2} \mathrm{~d} \\
1,8,15 \text { every } 28 \\
\text { days X } 3\end{array}$ & $\begin{array}{c}\text { C-DDP } 80 \\
\mathrm{mg} / \mathrm{m}^{2} \mathrm{~d} 1+\mathrm{G} \\
1000 \mathrm{mg} / \mathrm{m}^{2} \mathrm{~d} \\
1,8,15 \text { every } 28 \\
\text { days X } 3\end{array}$ & $\begin{array}{l}\mathrm{Cb} \text { AUC } 5 \mathrm{~d} 1+ \\
\mathrm{G} 1000 \mathrm{mg} / \mathrm{m}^{2} \\
\mathrm{~d} 1,8,15 \text { every } \\
28 \text { days X } 3-4\end{array}$ & $\begin{array}{c}\text { C-DDP } 75 \\
\mathrm{mg} / \mathrm{m}^{2} \mathrm{~d} 1+\mathrm{G} \\
1250 \mathrm{mg} / \mathrm{m}^{2} \\
\mathrm{~d} 1,8 \text { every } 21 \\
\text { days X } 3\end{array}$ & $\begin{array}{c}\text { Before 2003: } \\
\text { C-DDP } 80 \mathrm{mg} / \mathrm{m}^{2} \\
\mathrm{~d} 1+\mathrm{G} 1000 \mathrm{mg} / \mathrm{m}^{2} \\
\mathrm{~d} 1,8,15 \text { every } 28 \\
\text { days X 3; } \\
\text { After 2003: C-DDP } \\
80 \mathrm{mg} / \mathrm{m}^{2} \mathrm{~d} 1+\mathrm{P} \\
500 \mathrm{mg} / \mathrm{m}^{2} \mathrm{~d} 1 \\
\text { every } 21 \text { days X } 3\end{array}$ \\
\hline RR & $32 \%$ & NR & $33.3 \%$ & $26 \%$ & $32 \%$ \\
\hline $\mathrm{N}^{\circ} \mathrm{EPP}$ & $84 \%$ & $74 \%$ & $80.9 \%$ & $42 \%$ & - \\
\hline $\begin{array}{l}\text { Peri- } \\
\text { operative } \\
\text { mortality } \\
\text { rate }\end{array}$ & $0 \%$ & $2.2 \%$ & $0 \%$ & $0 \%$ & $3.2 \%$ \\
\hline RT & $\begin{array}{c}30 \mathrm{~Gy} \text { in } 2 \mathrm{~Gy} \\
\text { fractions + site } \\
\text { specific boost } \\
\text { to } 60 \mathrm{~Gy}\end{array}$ & $\begin{array}{l}50-60 \text { Gy in } 2 \\
\text { Gy fractions }\end{array}$ & $\begin{array}{c}45 \text { Gy in } 1.8 \text { Gy } \\
\text { fractions + } \\
\text { boost } 10-14 \text { Gy } \\
\text { in } 2 \text { Gy } \\
\text { fractions } \\
\end{array}$ & $\begin{array}{c}54 \text { Gy in } 1.8 \\
\text { fractions }\end{array}$ & $\begin{array}{c}30 \text { Gy in } 2 \text { Gy } \\
\text { fractions + boost } 20 \\
\text { Gy } \\
\text { or } \\
\text { IMRT } 45-55 \text { Gy }\end{array}$ \\
\hline TMT & $68 \%$ & $59 \%$ & $71 \%$ & $42 \%$ & - \\
\hline OS (ITT) & 23 months & 19.8 months & 25.5 months & 19 months & NR \\
\hline OS(EPP) & NR & $\begin{array}{c}\text { CT + EPP: } 23 \\
\text { months }\end{array}$ & 27.5 months & $\begin{array}{c}\text { CT + EPP + RT: } \\
33.5 \text { months }\end{array}$ & NR \\
\hline PFS & $\begin{array}{c}\mathrm{CT}+\mathrm{EPP}: 16.5 \\
\text { months }\end{array}$ & $\begin{array}{c}\text { CT + EPP: } 13.5 \\
\text { months }\end{array}$ & $\begin{array}{c}\text { CT + EPP: } 16.3 \\
\text { months }\end{array}$ & NR & NR \\
\hline
\end{tabular}

Table 1. Summary of studies with gemcitabine plus a platinum compound as neoadjuvant chemotherapy regimen in malignant mesothelioma patients who underwent trimodality treatment. (EPP: extrapleural pneumonectomy; TMT: trimodality treatment; ITT: intention to treat; NR: not reported; IMRT: intensity modulated radiation therapy; OS: overall survival; PFS: progression free survival; RR: response rate; CDDP: cisplatin; G: gemcitabine; Cb: Carboplatin; P: pemetrexed; CT: chemotherapy; RT: radiotherapy ) 


\begin{tabular}{|c|c|c|c|c|c|}
\hline Reference & $\begin{array}{l}\text { Buduhan et al., } \\
2009\end{array}$ & $\begin{array}{c}\text { de Perrot et al., } \\
2009\end{array}$ & $\begin{array}{l}\text { Krug et al., } \\
2009\end{array}$ & $\begin{array}{c}\text { Van Schil et al., } \\
2010\end{array}$ & $\begin{array}{l}\text { Rea et al., } \\
2011\end{array}$ \\
\hline $\mathrm{N}^{\circ}$ pts & 55 & 60 & 77 & 58 & 54 \\
\hline Study type & Retrospective & Retrospective & Prospective & Prospective & Prospective \\
\hline CT & $\begin{array}{c}\text { C-DDP/Cb +P; } \\
\text { C-DDP + MTX+ } \\
\text { Vb; } \\
\text { C-DDP+ G; other }\end{array}$ & $\begin{array}{c}\text { C-DDP +Vn; } \\
\text { C-DDP+ P; } \\
\text { C-DDP + R; } \\
\text { C-DDP + G X 2-6 }\end{array}$ & C-DDP + P X 3 & C-DDP + P X 3 & $\begin{array}{c}C-D D P+P X \\
3\end{array}$ \\
\hline $\mathrm{RR}$ & NR & NR & $32.5 \%$ & $43.9 \%$ & $29.6 \%$ \\
\hline $\mathrm{N}^{\circ} \mathrm{EPP}$ & $84 \%$ & $75 \%$ & $70.1 \%$ & $72.4 \%$ & $83.3 \%$ \\
\hline $\begin{array}{l}\text { Peri- } \\
\text { operative } \\
\text { mortality } \\
\text { rate }\end{array}$ & $4.3 \%$ & $6.7 \%$ & $4 \%$ & $6.5 \%$ & NR \\
\hline RT & $\begin{array}{c}\text { EBRT } 30 \mathrm{~Gy} \text { in } \\
\text { 1.8-2 Gy } \\
\text { fractions + boost } \\
\text { 9-18 Gy } \\
\text { or } \\
\text { IMRT } 50 \mathrm{~Gy}+ \\
\text { boost } 24 \mathrm{~Gy}\end{array}$ & $\begin{array}{c}50 \text { Gy in } 2 \text { Gy } \\
\text { fractions + boost } \\
10 \mathrm{~Gy} ; \\
\text { or } \\
\text { IMRT } 54 \text { Gy in } 1.8 \\
\text { Gy fractions }\end{array}$ & $\begin{array}{c}54 \text { Gy in } 1.8 \mathrm{~Gy} \\
\text { fractions }\end{array}$ & $\begin{array}{c}54 \text { Gy in } 1.8 \mathrm{~Gy} \\
\text { fractions }\end{array}$ & $\begin{array}{c}54 \text { Gy in } 1.8 \\
\text { Gy fractions } \\
\text { then emended } \\
\text { to } 50.4 \text { Gy in } \\
1.8 \mathrm{~Gy} \\
\text { fractions }\end{array}$ \\
\hline TMT & $69 \%$ & $50 \%$ & $52 \%$ & $64.9 \%$ & $40.7 \%$ \\
\hline OS (ITT) & NR & 14 months & 16.8 months & 18.4 months & 15.5 months \\
\hline OS (EPP) & $\begin{array}{c}\text { CT + EPP: } 24 \\
\text { months; } \\
\text { TMT: } 25 \text { months }\end{array}$ & NR & $\begin{array}{c}\text { CT+ EPP: } 21.9 \\
\text { months: } \\
\text { TMT: } 29.1 \\
\text { months }\end{array}$ & $\begin{array}{l}\text { TMT: } 33 \\
\text { months }\end{array}$ & NR \\
\hline PFS & NR & NR & $\begin{array}{c}\text { ITT: } 10.1 \\
\text { months; } \\
\text { CT + EPP: } 18.3 \\
\text { months }\end{array}$ & $\begin{array}{l}\text { ITT: } 13.9 \\
\text { months }\end{array}$ & $\begin{array}{l}\text { ITT EFS: } 6.9 \\
\text { months; } \\
\text { ITT PFS: } 8.6 \\
\text { months }\end{array}$ \\
\hline
\end{tabular}

Table 2. Summary of studies with pemetrexed plus a platinum compound as neoadjuvant chemotherapy regimen (EPP: extrapleural pneumonectomy; TMT: trimodality treatment; ITT: intention to treat; NR: not reported; NA: not available; EBRT: external beam radiotherapy; IMRT: intensity modulated radiation therapy; EFS: event free survival; OS: overall survival; PFS: progression free survival; RR: response rate; CDDP: cisplatin; G: gemcitabine; Cb: Carboplatin; P: pemetrexed; Vb: vinblastine; Vn: vinorelbine; R: raltitrexed; MTX: methotrexate; CT: chemotherapy; RT: radiotherapy )

When we analyze those results, we should consider the heterogeneity in terms of patient selection, treatment regimens, and methods for follow-up and overall survival analysis.

Over the years standard chemotherapy regimens for systemic treatment of malignant pleural mesothelioma has been changed. 
On the basis of results in the metastatic disease, the association of carboplatin or cisplatin plus gemcitabine was considered as an effective treatment (Byrne et al.,1999; Nowak et al., 2002; Favaretto et al., 2003; Castagneto et al., 2005; Kalmadi et al., 2008).

In 2003 and 2005 two phase III trials were published which reported striking results when cisplatin was associated to pemetrexed and raltitrexed respectively, compared to cisplatin as single agent in mesothelioma patients who were not eligible for curative surgery. Those regimens achieved a response rate of 30-40\%, a median progression free and overall survival of approximately 6 and 12 months respectively [(Van Meerbeeck et al., 2005; Vogelzang et al., 2003) .

After the two studies, a combination of cisplatin and an antifolate has become the golden standard in the first line treatment of malignant pleural mesothelioma patients not suitable for surgery and, subsequently, also in neoadjuvant setting.

\subsection{Doublet chemotherapy with gemcitabine combined to a platinum compound}

Since the end of the nineties, several groups analyzed the effectiveness and toxicity of gemcitabine combined to carboplatin or cisplatin in advanced mesothelioma patients (Byrne et al.,1999; Nowak et al., 2002; Favaretto et al., 2003; Castagneto et al., 2005; Kalmadi et al., 2008).

Those phase II trials showed a response rate ranging from $12 \%$ to $47 \%$, an overall survival from 10 to 16 months, and a progression free survival from 6 to 10 months.

In the wake of the results by Byrne and colleagues in metastatic disease, in 2004 a Swiss group conducted a pilot study investigating neoadjuvant chemotherapy with cisplatin and gemcitabine followed by extrapleural pneumonectomy with or without adjuvant radiotherapy in 19 malignant pleural mesothelioma patients with resectable disease (Weder et al., 2004). Induction chemotherapy consisted of three cycles of cisplatin $80 \mathrm{mg} / \mathrm{m}^{2}$ on day 1 plus gemcitabine $1000 \mathrm{mg} / \mathrm{m}^{2}$ on day $1,8,15$ every four weeks.

Extrapleural pneumonectomy was planned in all patients, while the total dose and fractionation of radiotherapy was decided according to resection margins and the target volume (hemitoracic three-dimensional conformal radiotherapy 30 to $60 \mathrm{~Gy}$ ). 13 (68\%) patients completed the entire trimodality treatment.

Response rate to neoadjuvant chemotherapy was 32\%; median overall survival in the intention-to-treat population was 23 months and disease free survival in patients who received preoperative chemotherapy and extrapleural pneumonectomy was 16.5 months.

The authors observed a higher compliance to neoadjuvant compared to the adjuvant chemotherapy adopted in a previous study; in fact, the three cycles of chemotherapy were administered successfully in $95 \%$ of the patients. The preoperative systemic approach did not increase perioperative mortality rate, and the morbidity rate was in line with previous experience. 
The good toxicity profile of chemotherapy regimen and the efficacy and activity results, higher than with other trimodality approaches, suggested further investigation of such treatment in a Swiss multicenter study (Weder et al., 2007).

The study investigated the feasibility of three cycles of cisplatin plus gemcitabine at the same doses previously adopted, followed by extrapleural pneumonectomy and adjuvant radiotherapy up to 60 Grey to the involved hemithorax, in 61 patients.

Quality of life assessment was one of the endpoints of the study.

Chemotherapy was administered to $95 \%$ of the patients, while the resection rate was $74 \%$. Complete resection (R0-R1) was achieved in 37 (61\%) of the 45 patients who underwent EPP.

Trimodality treatment was completed by 36 (59\%) patients, with an overall survival of 19.8 months in the intent-to-treat analysis and 23 months in patients who received both chemotherapy and surgery with or without adjuvant radiotherapy (Fig.1).

Median time to progression was 13.5 months, while no radiologic response rate was reported in the study. No significant worsening of quality of life was showed during the multimodality treatement. The postoperative mortality $(2.2 \%)$ and the morbidity rate $(35 \%)$ were acceptable and underline the need for experienced centre to follow such approach.

Considering the risk of increasing perioperative complications and postoperative mortality with the use of neoadjuvant chemotherapy, the administration of a chemotherapy regimen with lower toxicity seemed attractive.

Since 1996, our italian group tested the activity of carboplatin plus gemcitabine in a phase II study in 50 mesothelioma patients (Favaretto et al., 2003). We observed partial response in $26 \%$ of the patients, a median overall survival and progression free survival of about 16 and 10 months respectively, and an acceptable toxicity profile.

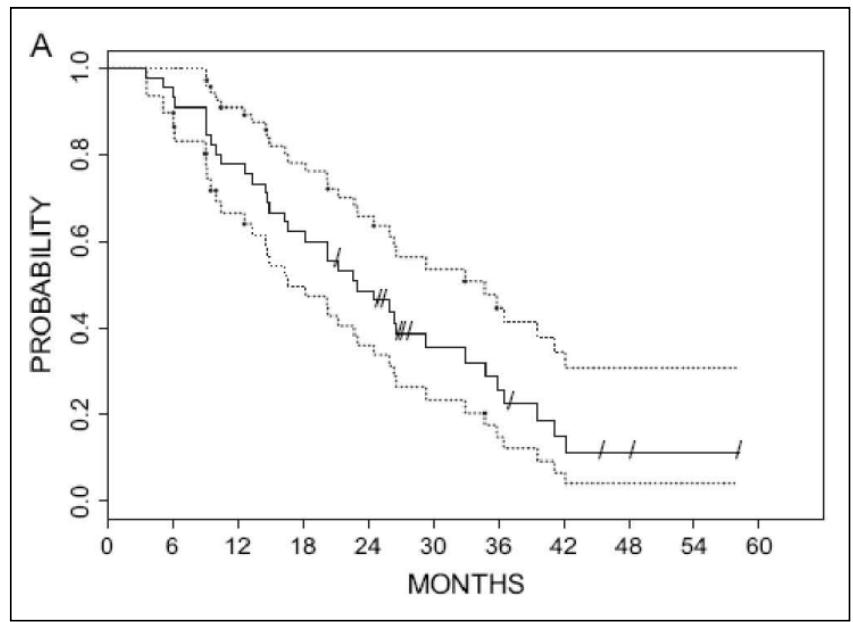

Figure 1. Overall survival in the intention-to-treat population . 
Those results led us to evaluate the same chemotherapy combination in the neoadjuvant setting of a multimodality approach in 21 patients with resectable disease (Rea et al., 2007). Patients with stage I to III, epithelial or mixed mesothelioma underwent three to four cycles of chemotherapy with carboplatin [area under the concentration -time curve (AUC) 5] on day 1 and gemcitabine $1000 \mathrm{mg} / \mathrm{m}^{2}$ on days 1,8,15 every four weeks. Patients with complete or partial response or stable disease underwent to extrapleural pneumonectomy within 4-6 weeks. Postoperative radiotherapy consisted of 45 Grey in 25 fractions to the hemitorax, with a boost dose of 10-14 Grey to high risk areas.

At the reassessment after induction chemotherapy, we observed 7 (33.3\%) partial response and $14(66.7 \%)$ stable disease.

The operability rate was about $81 \%$, and $71 \%$ of the patients completed the trimodality protocol.

The median overall survival was 25.5 months in the intent-to-treat population, and 27.5 months in patients who received extrapleural pneumonectomy (Fig. 2). Median time to relapse was 16.3 months.

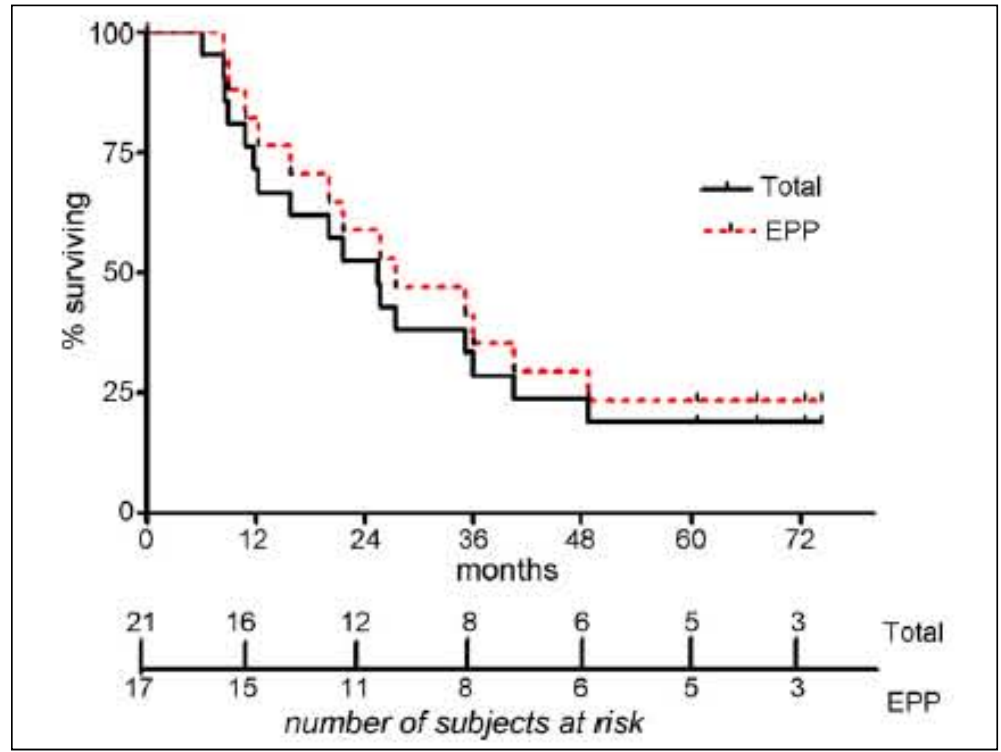

Figure 2. Overall survival in the intention to treat population and in patients who underwent extrapleural pneumonectomy for malignant pleural mesothelioma (Rea et al., 2007)

No intraoperative or perioperative morbidity was shown, while major complications were observed in $23.8 \%$ of the operated patients.

The absence of postoperative mortality characterizes another prospective study conducted at the Memorial Sloan-Kettering Cancer Center (Flores et al., 2006). 
From 2002 to 2004, 21 patients with locally advanced mesothelioma (stage III-IV) were entered into a phase II trial designed to test the feasibility of induction chemotherapy with cisplatin and gemcitabine followed by extrapleural pneumonectomy and external beam hemithoracic radiotherapy (EBRT). Chemotherapy included 4 cycles of gemcitabine 1250 $\mathrm{mg} / \mathrm{m}^{2}$ on days 1,8 combined with cisplatin $75 \mathrm{mg} / \mathrm{m}^{2}$ on day 1 every 21 days. Extrapleural pneumonectomy was performed within 3-5 weeks, in those patients who had resectable disease, followed by EBRT 54 Gy/30F starting 3-6 weeks after surgery. 19 patients started chemotherapy and $53 \%$ of them completed 4 cycles. Eight patients underwent EPP followed by EBRT, thus $42 \%$ of patients who completed the trimodality treatement.

Response to chemotherapy were: $26 \%$ partial response, $32 \%$ stable disease, $42 \%$ progressive disease.

Seven patients had grade 3 toxicity and one had grade 4 toxicity during chemotherapy, while only 2 (25\%) grade 3 and no grade 4 surgical complications occurred. Median overall survival in the intent-to-treat population and in patients who completed also the surgical procedure and radiotherapy was 19 and 33.5 months respectively. The rationale of the trial was to test the multimodality approach in high-risk patients with advanced disease, to reduce the risk of systemic relapase and to improve the outcome of those patients.

The study was prematurely interrupted because of another prospective competitive trial ongoing at the Center.

Those prospective studies adopting gemcitabine as the third-generation agent associated to platinum in the neoadjuvant setting agree that systemic treatment before surgery did not increase mortality and morbidity rate, provided that trimodality approach was managed by an experienced multidisciplinary team.

A retrospective study on 63 mesothelioma patients published in 2006 by the Swiss group (Opitz et al., 2006) aimed at investigating the incidence of postoperative complications in the context of trimodality treatment.

Most of the patients (75\%), who were included in the study before 2003, received three cycles of chemotherapy with cisplatin $80 \mathrm{mg} / \mathrm{m}^{2}$ on day 1 plus gemcitabine $1000 \mathrm{mg} / \mathrm{m}^{2}$ on day $1,8,15$ every four weeks. Since 2003 the patients $(25 \%)$ received induction chemotherapy based on three cycles of cisplatin $80 \mathrm{mg} / \mathrm{m}^{2}$ plus pemetrexed $500 \mathrm{mg} / \mathrm{m}^{2}$ on day 1 every three weeks.

Chemotherapy was followed by extrapleural pneumonectomy and radiotherapy (45 to 60 Grey to involved hemithorax including high risk areas).

Morbidity and mortality rate were $62 \%$ and $3.2 \%$ respectively. The most frequent postoperative complication was empyema $(15.8 \%)$, which was often associated to a longer duration of surgery. Other complications were chylothorax, patch failure, bleeding, herniation. Those complications were successfully managed by the surgical equipe, thanks to an increasing expertise during the years. Furthermore, the authors could predict and earlier treat those patients at higher risk of postoperative complications according to EORTC score, improving short-term outcome. 


\subsection{The advent of modern antifolate agents}

Pemetrexed is an antifolate agent which inhibits three target enzymes involved in purine and pyrimidine synthesis: dihydrofolate reductase, thymidylate synthase and glycinamide ribonucleotide formyltransferase.

On the basis of encouraging results of phase I trials in malignant pleural mesothelioma and a phase II study in non-small cell lung cancer, Vogelzang and colleagues conducted a phase III trial of pemetrexed, an antifolate agent, plus cisplatin compared to cisplatin as a single agent in 456 mesothelioma patients who were not elegible for curative surgery.

The doublet regimen achieved a significant improvement in terms of overall survival (12.1 versus 9.3 months, $p=0.02$ ), time to progression (5.7 versus 3.9 months, $p=0.001$ ) and response rate $(41.3 \%$ versus $16.7 \%$, $p<0.0001)$ compared to single agent chemotherapy (Vogelzang et al., 2003).

Two years later, data from another phase III trial were published, which showed a benefit in terms of overall (11.4 versus 8.8 months, $p=0.048$ ) and progression free survival (5.3 versus 4.0 months, $p=0.058)$, and response rate $(23.6 \%$ versus $13.6 \%, p=0.056)$ among patients treated with cisplatin plus raltitrexed, a different thymidylate synthase inhibitor, compared to cisplatin alone (Van Meerbeeck et al., 2005).

As previously mentioned, the combination of ciplatin to an antifolate agent became the golden standard in the systemic treatment of advanced malignant pleural mesothelioma.

More recent neoadjuvant trials have investigated the outcomes of trimodality treatment with this new regimen (Buduhan et al., 2009; De Perrot et al., 2009; Krug et al., 2009; Rea et al., 2011; Van Schil et al., 2010).

\subsubsection{Retrospective studies}

Two retrospective studies published in 2009 analyzed the outcomes of mesothelioma patients treated with neoadjuvant chemotherapy before surgery and radiotherapy. Chemotherapy regimen consisted of platinum-based doublet combined to different drugs, even if during the study time it was standardized to cisplatin plus pemetrexed.

The study by the Swedish Medical Center Institute (Buduhan et al., 2009), reviewed a consecutive group of 46 mesothelioma patients who were eligible for trimodality treatment. Preoperative chemotherapy administerd to the initial cohort of 55 patients was based on a platinum compound plus pemetrexed $(44 \%)$, cisplatin plus methotrexate plus vinblastine $(41 \%)$, cisplatin plus gemcitabine $(9 \%)$, other $(5 \%)$. Mediastinoscopy was performed within 3-5 weeks after completion of chemotherapy in those patients eligible for surgery, and the finding of malignant nodes was an absolute contraindication to extrapleural pneumonectomy. However, $44 \%$ of the patients were node positive at resection.

Extrapleural pneumonectomy was feasible in 46 patients $(84 \%)$, followed by adjuvant radiotherapy in 38 patients within 6-8 weeks from surgery. 
During the study time frame, radiotherapy was administered according to two different modalities: conventional external beam radiotherapy (EBRT) to a median dose of $30 \mathrm{~Gy}$ in fractions of 1.8-2 Gy (63\% of the patients) or intensity-modulated radiotherapy (IMRT) at the median dose of $50.4 \mathrm{~Gy} / 28 \mathrm{~F}$, with higher doses up to $60 \mathrm{~Gy}$ to the areas of residual disease (34\% of the patients).

Trimodality treatment was completed by $69 \%$ of the initial cohort and median survival time for those patients was 25 months; nodal positivity and macroscopically positive margins were considered as predictors of worse survival.

Postoperative mortality rate was $4.3 \%$; major comorbidities were present in $80 \%$ of the patients who underwent extrapleural pneumonectomy. Recurrent disease occurred in half of the patients in the ipsilateral hemithorax and it was more common among patients treated with EBRT compared to patients who received IMRT.

The main limitation of that study is the retrospective review of patients who started chemotherapy at different sites, so that it was not possible to determine which patients were selected for the trimodality treatment.

A mono-institutional experience was published during the same year (DePerrot et al., 2009), which retrospectively reviewed 60 cases of malignant pleural mesothelioma prospectively included in a trimodality protocol with induction chemotherapy, followed by extrapleural pneumonectomy and adjuvant high-dose hemithoracic radiation up to at least $50 \mathrm{~Gy}$. Patients with sarcomatoid mesothelioma were excluded.

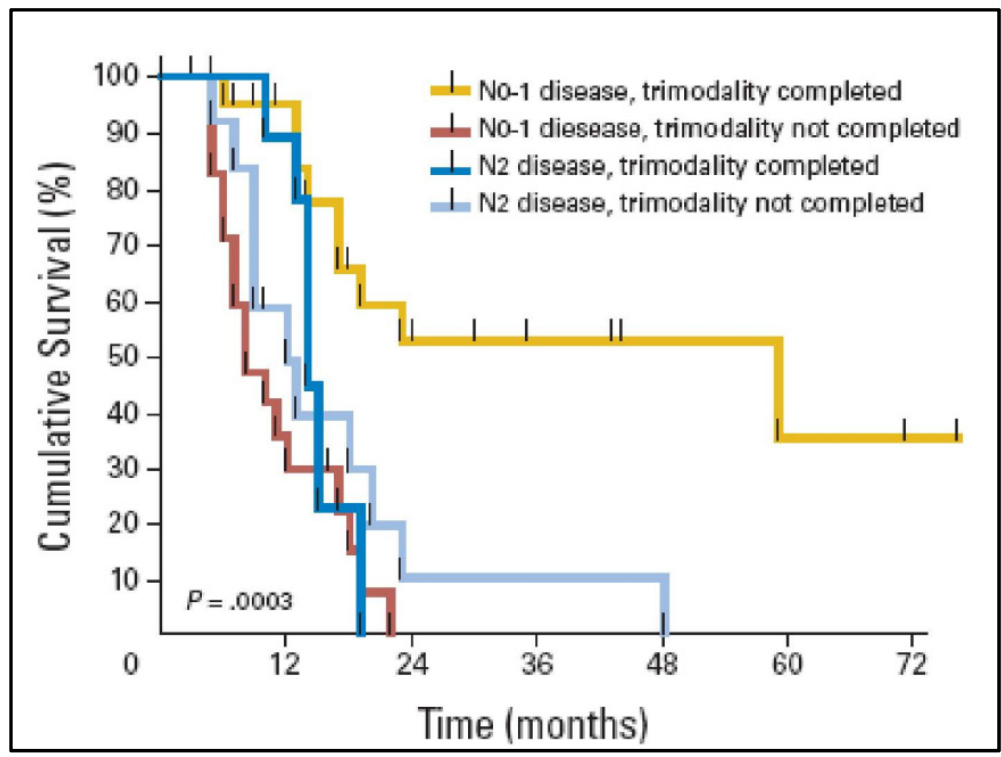

Figure 3. Survival according to mediastinal lymphonodes involvement and completion of the trimodality protocol, de Perrot et al., 2009 
Induction chemotherapy consisted of cisplatin combined with one of the following agents: vinorelbine $(43 \%)$, pemetrexed $(40 \%)$, raltitrexed $(10 \%)$, gemcitabine $(7 \%)$ for 2 to 6 cycles. Grade 3 (leucopenia) and 4 (pulmonary embolism) toxicity was described in $1(2 \%)$ and $3(5 \%)$ patients respectively.

45 patients $(75 \%)$ underwent extrapleural pneumonectomy, without significant difference between the induction regimens, while only half of the study population completed the trimodality treatment.

Complete resection was shown in $91 \%$ of the patients undergoing surgery. The perioperative mortality rate was $6.7 \%$.

Median overall survival in the intention-to-treat population was 14 months; chemotherapy regimen had no impact on overall survival, which was significantly better in patients without mediastinal node involvement who completed the trimodality treatment (59 months compared to 8 months in patients without node involvement but who did not complete the trimodality protocol). N2 involvement was a negative prognostic factor, without any difference between patients who completed or not the protocol. Nodal status showed a significant impact also on disease free survival (Fig.3).

Therefore, the conclusion of the study was to exclude patients with N2 disease from a trimodality protocol.

As well as in the study by Buduhan, also the retrospective analysis by de Perrot was limited by the administration of different chemotherapy regimens during the study time frame.

After the publication by Vogelzang, several prospective clinical trials which evaluated cisplatin plus pemetrexed as standard induction chemotherapy were designed.

\subsubsection{Prospective trials}

On the basis of the favourable results by Vogelzang, a multicenter phase II trial from the Memorial Sloan-Kettering Cancer Center group chose pemetrexed and cisplatin as induction chemotherapy regimen before extrapleural pneumonectomy and adjuvant radiotherapy, to assess the feasibility of such trimodality protocol (Krug et al., 2009).

A cohort of 77 patients was included in the protocol, but only 64 (83.1\%) completed four cycles of neoadjuvant chemotherapy with pemetrexed $500 \mathrm{mg} / \mathrm{m}^{2}$ plus cisplatin $75 \mathrm{mg} / \mathrm{m}^{2}$ on day 1 every three weeks. Extrapleural pneumonectomy was completed in $70.1 \%$ of the study population, while the trimodality protocol was completed by 40 (52\%) patients.

Radiological response to induction chemotherapy was: $1(1.3 \%)$ complete response, 24 (31.2\%) partial response, $36(46.8 \%)$ stable disease, $5(6.5 \%)$ progressive disease and 11 $(14.3 \%)$ patients with unknown or unavailable response.Three $(5.3 \%)$ pathological complete response were reported. Grade 3-4 haematological toxicity was observed in $7.8 \%$ of the 
patients. The postoperative mortality was $4 \%$ and the rate of postoperative complication was in line with the studies we reported previously.

Median survival and progression free survival in the intent-to-treat population were 16.8 and 10.1 months respectively (Fig.4). Overall survival was higher in those patients who completed extrapleural pneumonectomy (21.9 months) and radiotherapy (29.1 months). Furthermore, radiologic response to induction chemotherapy was demonstrated as a significant prognostic factor: patients with complete or partial response had a median overall survival of 26 months compared to 13.9 months in patients with stable and progressive disease. Recurrences occurred in $40.4 \%$ of the patients who underwent extrapleural pneumonectomy, with a median time to relapse of 18.3 months.

The study by Krug and colleagues was the largest prospective trial of trimodality treatment, and shows toxicity and efficacy data in line with previous studies. The authors emphasized the importance of patients selection and team experience in the management of early stage malignant pleural mesothelioma.
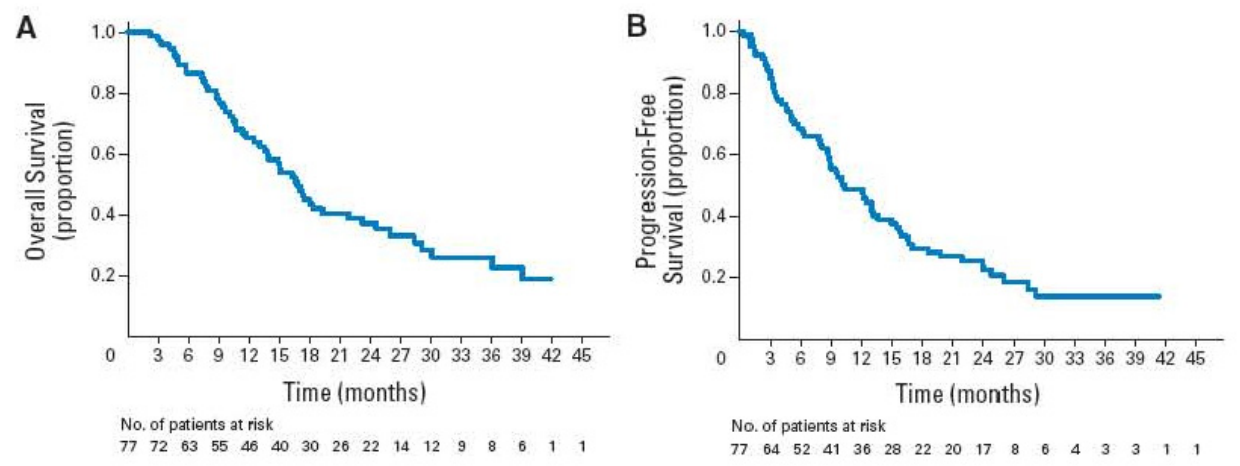

Figure 4. Overall survival (A) and progression free survival (B) in the intention to treat population of the study by Krug et al., 2009

The combination of cisplatin and pemetrexed was the induction regimen adopted from 2005 to 2007 in the multicenter study by European Organization for Research and Treatment of Cancer (EORTC) (Van Schil et al., 2010). 


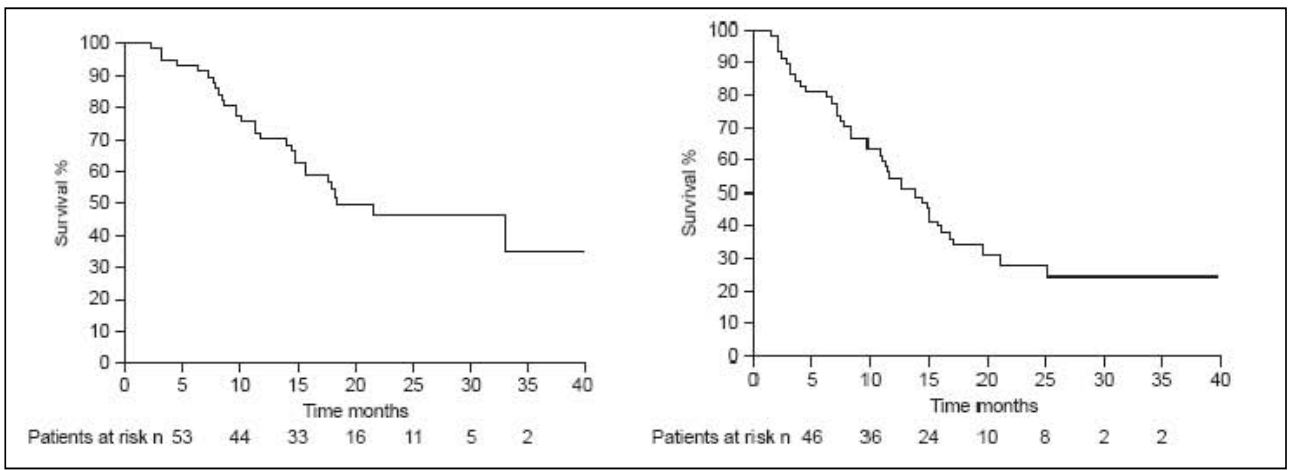

(A)

(B)

Figure 5. Overall survival and progression free survival (B) in the study population by Van Schil et al., 2010)

The primary endpoint of the study was to evaluate the "success of treatment" of a trimodality protocol based on induction chemotherapy with three cycles of cisplatin 75 $\mathrm{mg} / \mathrm{m}^{2}$ and pemetrexed $500 \mathrm{mg} / \mathrm{m}^{2}$ every three weeks followed by extrapleural pneumonectomy within 3-8 weeks after the last chemotherapy cycle and adjuvant hemithoracic radiotherapy (54 Gy/30 F).

Success of treatment was defined as the completion of the trimodality protocol within the defined time frames and a survival of 90 days without progression or grade 3-4 toxicity. Overall survival, progression free survival and toxicity were secondary endpoints.

58 patients were included in the study, 57 of them started chemotherapy and $55(94 \%)$ completed three cycles of chemotherapy. Extrapleural pneumonectomy was performed in $72.4 \%$ of the eligible patients, while $63.8 \%$ received also radiotherapy and completed the trimodality protocol.

Grade 3-4 toxicity after chemotherapy was observed in $27.7 \%$ of the patients, and persisted in $5.7 \%$ of the study population 90 days after the end of the protocol.

Radiological response at the end of induction chemotherapy was: complete in $24.6 \%$, partial in $19.3 \%$, stable in $42.1 \%$, progressive in $8.8 \%$ and not assessable in $5.3 \%$ of the patients. After surgery, postoperative complications were described in $82.6 \%$ of the patients, while postoperative mortality rate was $6.5 \%$. The primary endpoint was reached in $42.1 \%$ of the patients, that was lower than the $60 \%$ success rate needed to further investigate the trimodality treatment.

Median overall survival in the intention-to-treat population and in patients who completed the trimodality protocol was 18.4 and 33 months respectively; progression free survival for 57 eligible patients was 13.9 months (Fig.5). 
The predefined criteria of successful treatment were set looser, a higher number of patients reached the primary endpoint. The study remarked that trimodality treatment should be considered in centers with high levels of expertise and in the context of prospective clinical trials for selected early stage malignant mesothelioma patients.

A recent prospective phase II study presented at the latest ASCO (American Society of Clinical Oncology) meeting by our group evaluated neoadjuvant chemotherapy with pemetrexed plus cisplatin followed by extrapleural pneumonectomy (Rea et al., 2011) and hemithoracic radiation in 54 mesothelioma patients.

Chemotherapy was administered every three weeks for three cycles, at the following doses: cisplatin $75 \mathrm{mg} / \mathrm{m}^{2}$ and pemetrexed $500 \mathrm{mg} / \mathrm{m}^{2}$. Surgery was performed within 3 weeks after chemotherapy; radiotherapy maximum dose was changed during the study from 54 Gy to $50.4 \mathrm{~Gy}$, and the local radiation was planned within 4-12 weeks after extrapleural pneumonectomy. Chemotherapy was completed in $96 \%$ of the study population, while the trimodality treatment was completed in $22(40.7 \%)$ patients.

Out of 54 patients, $16(29.6 \%)$ showed partial response at the radiological assessment, 31 $(57.4 \%)$ showed stable disease, $4(7.4 \%)$ showed progressive disease.

Median event free survival was 6.9 months, median progression free survival: 8.6 months; median overall survival: 15.5 months; $67 \%$ of the patients experienced grade $3-$ 4 toxicity.

In line with the previous studies in the same setting, the trimodality protocol presented in the study seemed feasible with manageable toxicity, provided that cardiopulmonary function is closely monitored.

\subsection{The MARS trial}

What is the chance of extrapleural pneumonectomy in the management of malignant pleural mesothelioma? This was the big question from which the Mesothelioma And Radical Surgery (MARS) trial rose in 2005 (Treasure et al.,2006, 2009, 2011) (Fig. 6).

The aim of the study was to put an end to the debate between believers and doubters about that surgical procedure, through a randomization between induction chemotherapy followed by extrapleural pneumonectomy and induction chemotherapy without EPP.

Initially, to assess the patients' compliance and the recruitment rate, a feasibility exploratory analysis was performed which randomized 50 patients in 1 year between the two treatment arms. The randomization seemed to be feasible in $45 \%$ of the patients included in the study, and a larger trial was published two years later, with the aim of evaluating the clinical outcome in randomly assigned patients.

The MARS study was a multicenter randomized controlled trial in 12 United Kingdom hospitals, with a two-stage consent process, before registration and before randomization (Fig.6). 


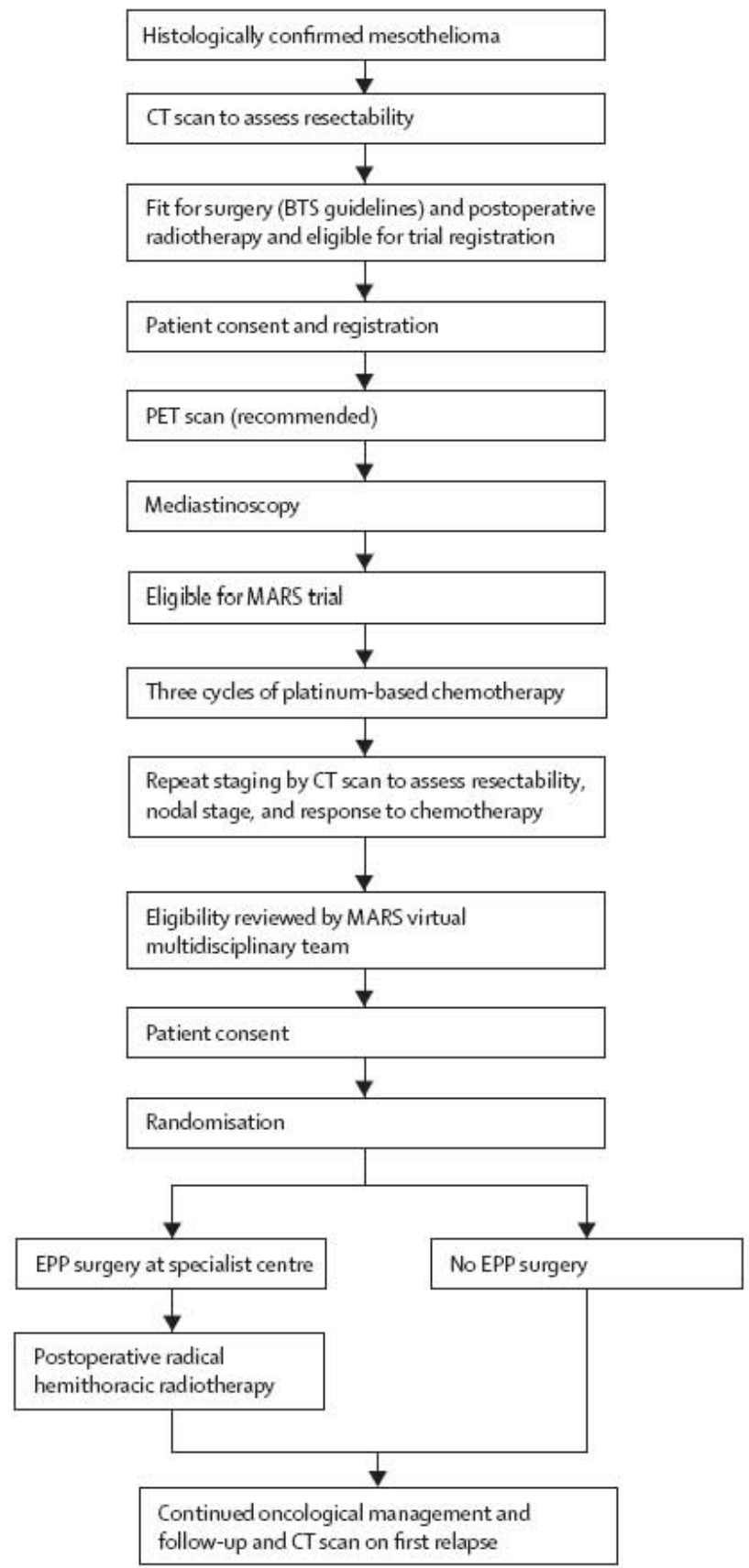

Figure 6. Study design of the Mesothelioma And Radical Surgery (MARS) trial. 
After the first informed consent and registration, 112 patients underwent mediastinoscopy and PET, then 94 received at least one cycle of chemotherapy; in particular 83 (74\%) of them received three cycles of platinum-based chemotherapy. The most common chemotherapy regimen adopted was cisplatin and gemcitabine (40\%), followed by cisplatin and pemetrexed (26\%), cisplatin and mitomycin and vinblastine $(21 \%)$. At the end of chemotherapy patients underwent CT scan and they were re-evaluated for the eligibility to extrapleural pneumonectomy.

A second informed consent was provided to 50 patients before randomization. The proportion of patients who accepted to enter the registration phase was carefully documented.

Patients in the control arm were eligible for any oncological treatment, which included chemotherapy, radiotherapy, every surgical procedure but EPP, full supportive care.

24 patients were assigned to extrapleural pneumonectomy, 26 to no EPP. Among patients in the first group, 16 (67\%) completed extrapleural pneumonectomy; perioperative deaths occurred in $15.8 \%$ of the patients and perioperative complications in $69 \%$ of the patients. Half of the patients who underwent extrapleural pneumonectomy received radiotherapy.

As far as the second group is concerned, further oncological treatment was administered to $32 \%$ of them; in particular, three patients received extrapleural pneumonectomy outside the trial. Among the 30 deaths within the first 24.7 months from randomization, 4 were perioperative events: 3 in the EPP arm, and 1 in the no EPP arm which occurred in a patient who underwent EPP outside the clinical trial.

Median survival from randomization was 14.4 months in patients addressed to EPP and 19.5 months in patients who did not undergo extrapleural pneumonectomy $(p=0.016$, after adjustment for prognostic factors). Median recurrence free survival in EPP group was 7.6 months; median progression free survival in no EPP group was 9.0 months.

Median quality of life seemed better in those patients who did not undergo extrapleural pneumonectomy; the lowest scores in EPP group were observed shortly after surgery.

The MARS trial was the first study which randomized between extrapleural pneumonectomy and no extrapleural pneumonectomy in the management of malignant pleural mesothelioma. The study population was small but the conclusion of the trial raised the issue of a less invasive approach as suitable treatment of malignant pleural mesothelioma. Those results are supported by previous data from the surgical group of Flores where extrapleural pneumonectomy was compared to pleurectomy/decortication in a multi-institutional trial where 663 patients consecutively underwent one of the two surgical procedures. The mortality rate was higher in patients treated with extrapleural pneumonectomy (7\%) compared to patients who underwent pleurectomy/decortication (4\%) (Flores et al., 2008).. 
Overall survival was longer in those patients who were treated with pleurectomy/decortication; however gender, stage, histotype were significant factors which impacted the patients' outcome.

In the future, a randomized study to evaluate the outcome of patients treated with pleurectomy/decortication is needed.

\section{Risks and benefits of neoadjuvant chemotherapy of malignant pleural mesothelioma}

Platinum-based chemotherapy plus gemcitabine or pemetrexed for 3 to 4 cycles followed by surgery and postoperative high-dose radiotherapy showed the best results in terms of overall and progression free survival. However, patients were selected without a control group, and a randomized controlled trial to define the best treatment is still lacking.

Multimodality treatment is long. For the remarkable physical and psychological distress at the end of this invasive approach it is important to look for a strong evidence of the benefits.

The MARS trial tried to answer the question about the benefits of extrapleural pneumonectomy in the context of trimodality treatment. The results were controversial, so the debate inside the scientific community is still open.

Some thoracic surgeons and clinicians believe there is sufficient evidence to support the use of extrapleural pneumonectomy in selected patients; on the other side, the "doubters" underline the scientific bias inside the patients' selection: the improvement in overall survival with EPP might be the result of the exclusion of patients not suitable for surgery, therefore with unfavourable features.

The MARS study was the only randomized trial which compared EPP to no EPP, showing no benefit for mesothelioma patients who underwent such surgical procedure.

The optimal treatment for malignant pleural mesothelioma is still a matter of debate not only as far as the surgery is concerned.

In the context of a multimodality treatment, chemotherapy was administered as adjuvant treatment after surgery for many years, while the administration of chemotherapy in the induction phase was recently introduced in the clinical practice.

As already mentioned, the potential benefits of preoperative chemotherapy are the early eradication of the circulating metastases and the shrinkage of tumor size; the first could reduce the rate of distant recurrences and the second could make the surgery possible for inoperable tumors or easier for operable but extensive disease. Furthermore, the difficult delivery of both radiotherapy and chemotherapy after surgery was another reason to administer chemotherapy as the first step of the trimodality protocol aiming at a better tolerance of the side effects. 
On the other side the delay of the surgical procedure is a disadvantage of neoadjuvant chemotherapy, especially when chemotherapy is not effective

Some authors reported the impairment of cardiorespiratory function as another detrimental effect of induction chemotherapy and showed an increased risk of perioperative morbidity and mortality.

\subsection{Effects of neoadjuvant chemotherapy on the risk of perioperative morbidity and mortality}

Many chemotherapeutic agents can cause lung and heart damage even if the type of the injury and its pathogenesis is unclear; however, the alveolo-capillary membrane seems to be the main target of chemotherapy.

Several evidences reported an increased mortality rate and risk of respiratory complications after induction chemotherapy in lung cancer, especially in those patients who received pneumonectomy.

In 2005, data from 74 mesothelioma patients who underwent EPP were analyzed to assess the incidence of perioperative complications (Stewart et al., 2005).

The authors identified three preoperative variables associated to perioperative complications.

Neoadjuvant chemotherapy with cisplatin doublet in combination with gemcitabine (9), pemetrexed (5) or vinorelbine (1) was administered in $20 \%$ of the study population, and it was associated to a higher risk of acute lung injury and symptomatic mediastinal shift. Long-standing operations were associated to increased risk of technical and gastrointestinal complications; finally, procedures on the right lung seemed to increase the risk of postoperative pneumonia and overall risk of perioperative mortality.

On the basis of previous results, our group conducted a prospective study to evaluate the effect of neoadjuvant chemotherapy on lung function and exercise capacity in 36 mesothelioma patients suitable for extrapleural pneumonectomy (Marulli et al., 2010).

Pulmonary function tests were performed twice: after the diagnostic video-assisted thoracoscopic surgery and before the first cycle of chemotherapy, and then four weeks after the last chemotherapy cycle. The tests comprised a spirometry with the measurement of slow and forced vital capacity ( $\mathrm{Vc}_{\mathrm{c}}$ and FVC), forced expiratory volume in the first second (FEV1), total lung capacity and diffusing capacity of the lung for carbon monoxide (DLCO); and an incremental exercise test using a cycle ergometer to assess the oxygen uptake $\left(\mathrm{VO}_{2}\right)$, $\mathrm{CO}_{2}$ production $\left(\mathrm{VCO}_{2}\right)$ and minute ventilation (VE). Blood gas analysis was also performed.

Among the 36 patients included in the study, 52.8\% received three cycles of induction chemotherapy with carboplatin (AUC 5) and pemetrexed $\left(500 \mathrm{mg} / \mathrm{m}^{2}\right)$ on day 1 every three weeks; $47.2 \%$ received pemetrexed with cisplatin $\left(75 \mathrm{mg} / \mathrm{m}^{2}\right)$ on day 1 every 21 days. 
Radiologic assessment after chemotehrapy showed a $44.5 \%$ partial response, stable disease in $47.2 \%$ and progressive disease in $8.3 \%$. Performance status after induction chemotherapy improved in $27.8 \%$, was stable in $50 \%$ and worsened in $22.2 \%$ of the patients.

All the parameters estimated for the lung function and exercise tests improved after preoperative chemotherapy; in particular FEV1, oxygen pressure $\left(\mathrm{PaO}_{2}\right)$ at rest and the peak of exercise and $\mathrm{VO}_{2}$. A significant improvement of the lung volume indexes was observed in particular for those patients who achieved a partial response to induction chemotherapy; the results of the stratified analysis by response were explained by the cytoreductive effects of chemotherapy on the tumor mass, thus improving the lung expansion.

As already mentioned, chemotherapy could affect the lung function by decreasing the efficiency of alveolar-capillary membrane. In our study, gas exchange parameters were not impacted by induction chemotherapy, probably related to an improvement in alveolar volume. Preoperative chemotherapy seemed not to compromise the cardiopulmonary effectiveness to undergo EPP; such conclusion seems in line with the results of previous studies about trimodality treatment, which did not show increased perioperative mortality (table 1 and 2).

\section{Potential benefits of a less aggressive approach in the management of malignant pleural mesothelioma: Which is the best chemotherapy regimen?}

Trimodality treatment is one of the more invasive approaches in cancer management, and patients might suffer from perioperative complications due to the impaired clinical conditions after induction treatments.

Two surgical techniques are applied to the removal of malignant pleural mesothelioma: extrapleural pneumonectomy and pleurectomy/decortication.

Extrapleural pneumonectomy consists of en bloc resection of the pleura, lung, diaphragm, and pericardium, while pleurectomy/decortication removes the involved pleura and makes the underlying lung free to expand and fill the pleural cavity.

Despite previous studies did not show a significant rising in mortality and morbidity within trimodality protocols (Buduhan et al., 2009; De Perrot et al., 2009; Flores et al., 2006; Krug et al., 2009; Opitz et al., 2006; Rea et al., 2007, 2011; Van Schil et al., 2010, Weder et al., 2004, 2007) extrapleural pneumonectomy is still a controversial approach, especially in the light of the MARS trial results (Treasure et al., 2011).

The choice of extrapleural pneumonectomy (EPP) rather than pleurectomy/decortication $(\mathrm{P} / \mathrm{D})$ is not based on scientific evidences but on the surgeon decision.

In 2008, Flores and his group analyzed the outcome of the two surgical procedures in 663 malignant pleural mesothelioma patients (Flores et al., 2008). $60 \%$ of the study population 
received extrapleural pneumonectomy with a perioperative mortality of $7 \%$. Perioperative mortality in the patients who received pleurectomy/decortication was $4 \%$.

The decision to perform EPP rather than P/D was based on patients' clinical condition, intraoperative findings and tumor stage.

In the EPP group there was a higher proportion of patients who received a multimodality treatment, while in $\mathrm{P} / \mathrm{D}$ group, elderly patients and early stage tumors were included.

Median overall survival and 5 -year survival in all the patients were 14 months and 12\% respectively. Significant prognostic variables were stage, gender, asbestos exposure, histology, and multimodality treatment.

When overall survival was analyzed in the two subgroups, extrapleural pneumonectomy was associated to a worse prognosis, irrespective of stage and perioperative mortality (12 versus 16 months, $\mathrm{p}<0.001)$. The difference seemed less evident when survival data were analyzed in a multivariate analysis with other prognostic factors.

The main limitation of the study was the retrospective data analysis which did not allow any definitive conclusion about the outcome of the two surgical procedures.

In line with the results of the MARS study, a randomized trial which analyze the impact of pleurectomy/decortication on the overall survival of mesothelioma patients could define the role of lung-sparing surgery within a trimodality protocol.

As already mentioned, the role of chemotherapy in the multimodality management of malignant pleural mesothelioma aims at reducing distant recurrences.

So far, no randomized trial has compared different chemotherapy regimens in the induction phase of a trimodality protocol.

It is possible that the integration of less invasive treatments lead to a better outcome of mesothelioma patients.

Carboplatin is often preferred to cisplatin in the systemic treatment of cancer because it shows a lower incidence of neurotoxicity, nephrotoxicity, nausea and vomiting. When carboplatin substituted cisplatin in malignant pleural mesothelioma patients not eligible for surgery, it showed comparable results in terms of activity (Castagneto et al., 2008; Ceresoli et al., 2006; Favaretto et al., 2003).

Recently, our group retrospectively analyzed the feasibility of pemetrexed plus carboplatin or cisplatin as preoperative chemotherapy of malignant pleural mesothelioma (Pasello et al., 2011). 54 patients were consecutively included in a trimodality protocol based on preoperative chemotherapy followed by surgery and adjuvant radiotherapy; neoadjuvant chemotherapy was based on three cycles of pemetrexed $\left(500 \mathrm{mg} / \mathrm{m}^{2}\right)$ plus carboplatin (AUC5) on day 1 every three weeks in 30 patients; 24 patients received pemetrexed (500 $\left.\mathrm{mg} / \mathrm{m}^{2}\right)$ plus cisplatin $\left(75 \mathrm{mg} / \mathrm{m}^{2}\right)$ on day 1 every 21 days. 
We observed a higher incidence of grade 2-3 cumulative asthenia and worsening of performance status in the subgroup of patients who received cisplatin rather than carboplatin. Furthermore the postoperative mortality was $4 \%$ among patients treated with cisplatin compared to $0 \%$ among patients who received carboplatin in the induction chemotherapy regimen. We observed no difference in terms of disease control rate and progression free survival between the two treatment arms, while a longer overall survival (118 versus 66 weeks) was shown in patients treated with carboplatin rather than cisplatin. At the multivariate analysis, non-epithelial histology and cisplatin-based chemotherapy were associated to a worse prognosis. It is possible that a less aggressive chemotherapy regimen could improve the outcome of trimodality treatment, and allows second-line treatments to a higher proportion of patients. In our study, in fact, at the time of disease progression $37 \%$ of the patients previously treated with cisplatin received a second-line treatment, compared to $58 \%$ of the patients treated with carboplatin in the first-line.

Second line chemotherapy could have an impact on overall survival of mesothelioma patients, as already shown by Manegold and colleagues in the retrospective analysis of patients from the phase III study by Vogelzang in 2003 (Manegold et al., 2005). Another explanation for the longer survival in patients treated with carboplatin might be the higher number of sarcomatoid mesothelioma patients in the subgroup of patients treated with cisplatin.

As far as the doublet carboplatin and pemetrexed doublet concerns, another group recently compared that regimens to cisplatin plus pemetrexed in 54 malignant pleural mesothelioma patients (Emri et al., 2011).

Chemotherapy consisted of pemetrexed plus carboplatin in 34 patients and plus cisplatin in 20 patients; median number of cycles was 6 . Surgery was performed in $41 \%$ of the study population, and radiotherapy in $29(54 \%)$ patients.

Median overall survival in all the 54 patients was 16 months. When the authors compared overall survival in the two treatment subgroups, they observed a significantly longer survival in patients treated with carboplatin (20 months compared to 15 months in cisplatinsubgroup), while no difference in terms of time to relapse and response rate was observed between the two arms.

On the basis of those results, prospective randomized clinical trials should be designed to evaluate toxicity profile, response rate, survival data of different chemotherapy regimens in the neoadjuvant treatement of malignant mesothelioma patients.

\section{Conclusion}

Despite the improvement in diagnosis and treatment, malignant pleural mesothelioma patients still have a dismal prognosis, because of the low response rate to chemotherapy and the early relapses. 
The integration of systemic and local treatments in the multimodality approach seemed to reduce local and distant recurrences, and subsequently to improve the overall survival of affected patients.

The optimal sequence of chemotherapy, radiotherapy and surgery has not been defined yet, even though trimodality protocols of neoadjuvant chemotherapy followed by extrapleural pneumonectomy and adjuvant radiotherapy achieved the best results, with overall survival longer than 20 months in selected patients.

The lack of a randomized study in this setting and the variability among the available phase II studies does not allow to draw any conclusion about the best treatment for mesothelioma patients. Furthermore, those studies evaluated data from selected patients who were eligible for trimodality treatment, subsequently introducing a bias in the final data analysis.

The role of EPP is still a matter of debate, and the recent results of the MARS trial suggests a potential role of a less invasive surgery, such as pleurectomy/decortication.

The optimal chemotherapy regimen in the induction phase is not defined, and prospective randomized studies assessing toxicity and survival data of different protocols should be designed.

To improve the response rate to chemotherapy regimen, new biologic agents should be introduced in the clinical practice, so that the best results in terms of tumor shrinkage and low toxicity could be achieved.

The optimal relationship between toxicity profile and clinical benefit should be investigated especially in the context of a trimodality approach, which implies a long-term treatment in patients who are often elderly and with impaired performance status.

\section{Author details}

Giulia Pasello and Adolfo Favaretto

Second Medical Oncology Dept., Istituto Oncologico Veneto, Italy

\section{References}

Buduhan, G., Menon, S., Aye, R., Louie, B., Mehta, V., \& Vallières, E. (2009). Trimodality Therapy for Malignant Pleural Mesothelioma. The Annals of Thoracic Surgery, Vol.8, No.3, (September 2009), pp.870-876

Burdett, S., Stewart, L.A., \& Rydzewska, L. (2006). A Systematic Review and Meta-analysis of the Literature: Chemotherapy and Surgery versus Surgery Alone in Non-small Cell Lung Cancer. Journal of Thoracic Oncology, Vol.1, No. 7, (September 2006), pp. 611-621, ISSN 1556-0864/06/0107-0611 
Burdett, S., Stewart, L.A., \& Rydzewska, L. (2007). Chemotherapy and surgery versus surgery alone in non-small cell lung cancer. Cochrane database of systematic reviews, Vol.18, No.3, (July 2007), CD 006157

Byrne, M.J., Davidson, J.A., Musk, A.W., Dewar, J., van Hazel, G., Buck, M., de Klerk, N.H., \& Robinson, B.W. (1999). Cisplatin and gemcitabine treatment for malignant mesothelioma: a phase II study. Journal of Clinical Oncology, Vol.17, No 1, (January 1999), pp. 25-30.

Cao, C.Q., Yan, T.D., Bannon, P.G., \& McCaughan, B.C. (2010). A systematic review of extrapleural pneumonectomy for malignant pleural mesothelioma. Journal of Thoracic Oncology, Vol.5, No.10, (October 2010), pp.1692-1703, ISSN 1556-0864/10/0510-1692

Castagneto, B., Zai, S., Dongiovanni, D., Muzio, A., Bretti, S., Numico, G., Botta, M., \& Sinaccio, G. (2005). Cisplatin and gemcitabine in malignant pleural mesothelioma: a phase II study. American Journal of Clinical Oncology, Vol. 28, No. 3, (June 2005), pp. 223226

Castagneto, B., Botta, M., Aitini, E., Spigno, F., Degiovanni, D., Alabiso, O., Serra, M., Muzio, A., Carbone, R., Buosi, R., Galbusera, V., Piccolini, E., Giaretto, L., Rebella, L., \& Mencoboni,M. (2008). Phase II study of pemetrexed in combination with carboplatin in patients with malignant pleural mesothelioma (MPM). Annals of Oncology, Vol.19, No. 2, (February 2008), pp. 370-373

Ceresoli, G.L., Zucali, P.A., Favaretto, A.G., Grossi, F., Bidoli, P., Del Conte, G., Ceribelli, A., Bearz, A., Morenghi, E., Cavina, R., Marangolo, M., Parra, H.J., \& Santoro, A. (2006). Phase II study of pemetrexed plus carboplatin in malignant pleural mesothelioma. Journal of Clinical Oncology, Vol. 24, No. 9, (March 2006), pp. 1443-1448

de Perrot, M., Feld, R., Cho, B.C.J., Bezjak, A., Anraku, M., Burkes, R., Roberts, H., Tsao, M.S., Leighl, N., Keshavjee, S., \& Johnston, M.R. (2009). Trimodality Therapy With Induction Chemotherapy Followed by Extrapleural Pneumonectomy and Adjuvant High-Dose Hemithoracic Radiation for Malignant Pleural Mesothelioma. Journal of Clinical Oncology, Vol. 27, No. 9, (March 2009), pp. 1413-1418

Emri, S., Hurmuz, P., Kadilar, C., Cangir, A.K., Zorlu, F., Dogan, R., \& Akyol, F. (2011). Pemetrexed-carboplatin doublets showed better mediab survival than pemetrexed-cisplatin in the treatment of Turkish malignant pleural mesothelioma patients. Journal of Thoracic Oncology, Vol. 6, No.6 (S2), (June 2011), pp. S 1671, Abtract $n^{\circ}$ P3.302

Favaretto, A.G., Aversa, S.M.L, Paccagnella, A., De Pangher Manzini, V., Palmisano, V., Oniga, F., Stefani, M., Rea, F., Bortolotti, L., Loreggian, L., \& Monfardini, S. (2003). Gemcitabine Combined with Carboplatin in Patients with Malignant Pleural Mesothelioma. A Multicentric Phase II Study. Cancer, Vol. 97, No. 11, (June 2003), pp. 2791-2797.

Flores, R.M., Krug, L.M., Rosenzweig, K.E., Venkatraman, E., Vincent, A., Heelan, R., Akhurst, T., \& Rusch, V.W. (2006). Induction Chemotherapy, Extrapleural Pneumonectomy, and Postoperative High-Dose Radiotherapy for LocallyAdvanced 
Malignant Pleural Mesothelioma: A Phase II Trial. Journal of Thoracic Oncology. Vol. 1, No. 4, (May 2006), pp. 289-295, ISSN 1556-0864/06/0104-0289

Flores, R.M., Pass, H.I., Seshan, V.E., Dycoco, J., Zakowski, M., Carbone, M., Bains, M.S., \& Rusch, V.W. (2008). Extrapleural pneumonectomy versus pleurectomy/decortication in the surgical management of malignant pleural mesothelioma: results in 663 patients. Journal of Thoracic and Cardiovascular Surgery, Vol. 135, No. 3, (March 2008), pp. 620-626

Kalmadi, S.R., Rankin, C., Kraut, M.J., Jacobs, A.D., Petrylak, D.P., Adelstein, D.J., Keohan, M.L., Taub, R.N., \& Borden, E.C. (2008). Gemcitabine and cisplatin in unresectable malignant mesothelioma of the pleura: a phase II study of the Southwest Oncology Group (SWOG 9810). Lung Cancer, Vol. 60, No. 2, (May 2008), pp. 259-263

Krug, L.M., Pass, H.I., Rusch, V.W., Kindler, H.L., Sugarbaker, D.J., Rosenzweig, K.E., Flores, R., Friedberg, J.S., Pisters, K., Monberg, M., Obasaju, C.K., \& Vogelzang, N.J. (2009). Multicenter Phase II Trial of Neoadjuvant Pemetrexed Plus Cisplatin Followed by Extrapleural Pneumonectomy and Radiation for Malignant Pleural Mesothelioma. Journal of Clinical Oncology, Vol. 27, No. 18, (June 2009), pp. 3007-3013

Manegold, C., Symanowski, J., Gatzemeier, U., Reck, M., von Pawel, J., Kortsik, C., Nackaerts, K., Lianes, P., \& Vogelzang, N.J. (2005). Second-line (post-study) chemotherapy received by patients treated in the phase III trial of pemetrexed plus cisplatin versus cisplatin alone in malignant pleural mesothelioma. Annals of Oncology, Vol. 16, No. 6, (June 2005), pp. 923-927

Marinaccio, A., Binazzi, A., Cauzillo, G., Cavone, D., Zotti, R.D., Ferrante, P., Gennaro, V., Gorini, G., Menegozzo, M., Mensi, C., Merler, E., Mirabelli, D., Montanaro, F., Musti, M., Pannelli, F., Romanelli, A., Scarselli, A., \& Tumino, R. (2007). Analysis of latency time and its determinants in asbestos related malignant mesothelioma cases of the Italian register. European Journal of Cancer, Vol. 43, No. 18, (December 2007), pp.27228.

Marulli, G., Rea, F., Nicotra, S., Favaretto, A.G., Perissinotto, E., Chizzolini, M., Vianello, A., \& Braccioni, F. (2010). Effect of induction chemotherapy on lung function and exercise capacity in patients affected by malignant pleural mesothelioma. European Journal of Cardiothoracic Surgery, Vol. 37, No. 6, (June 2010), pp. 1464-1469.

Nowak, A., Byrne, M.J., Williamson, R., Ryan, G., Segal, A., Fielding, D., Mitchell, P., Musk, A.W., \& Robinson, B.W. (2002). A multicentre phase II study of cisplatin and gemcitabine for malignant mesothelioma. British Journal of Cancer, Vol. 87, No. 5, (August 2002), pp. 491-496

Opitz, I., Kestenholz, P., Lardinois, D., Muller, M., Rousson, V., Schneiter, D., Stahel, R., \& Weder, W. (2006). Incidence and management of complications after neoadjuvant chemotherapy followed by extrapleural pneumonectomy for malignant pleural mesothelioma. European Journal of Cardiothoracic Surgery, Vol. 29, No. 4, (April 2006), pp. 579-584 
Pasello, G., Marulli, G., Nicotra, S., Rea, F., Loreggian, L., Bonanno, L., \& Favaretto, A.G. (2011). Pemetrexed/Carboplatin or Pemetrexed/Cisplatin as first line treatment of malignant pleural mesotelioma (MPM): tolerability and response rate in operable patients. Journal of Thoracic Oncology, Vol. 6, No.6 (S2), (June 2011), pp. S1367, Abtract n ${ }^{\circ}$ P3.297

Rea, F., Marulli, G., Bortolotti, L., Breda, C., Favaretto, A.G., Loreggian, L., \& Sartori, F. (2007). Induction chemotherapy, extrapleural pneumonectomy (EPP) and adjuvant hemi-thoracic radiation in malignant pleural mesothelioma (MPM): Feasibility and results. Lung Cancer, Vol. 57, No. 1, pp. 87-95

Rea, F., Favaretto, A.G., Marulli, G., Spaggiari, L., De Pas, T.M., Ceribelli, A., Paccagnella, A., Crivellari, G., Russo, F., Ceccarelli, M., \& Facciolo, F. (2011). Journal of Clinical Oncology, Vol. 29, Abstract 7090

Rice, D.C., Stevens, C.W., Correa, A.M., Vaporciyan, A.A., Tsao, A., Forster, K.M., Walsh, G.L., Swisher, S.G., Hofstetter, W.L., Mehran, R.J., Roth, J.A., Liao, Z., \& Smythe, W.R. Outcomes after extrapleural pneumonectomy and intensity-modulated radiation therapy for malignant pleural mesothelioma. (2007) Annals of Thoracic Surgery, Vol. 84, No. 5, (November 2007), pp. 1692-1693

Rosell, R., Gòmez-Codina, J., Camps, C., Maestre, J., Padille, J., Canto, A., Mate, J.L., Li, S., Roig, J., Olazabal, A., Canela, M., Ariza, A., Skacel, Z., Morera-Prat, J., \& Abad, A. (1994). A randomized trial comparing preoperative chemotherapy plus surgery with surgery alone in patients with non-small-cell lung cancer. New England Journal of Medicine, Vol. 330, No. 3, (January 1994), pp. 153-158

Roth, J.A., Fossella, F., Komaki, R., Ryan, M.B., Putnam, J.B.J., Lee, J.S., Dhingra, H., De Caro, L., Chasen, M., Mc Gavran, M., Atkinson, E.N., \& Hong, W.K. (1994). A Randomized Trial Comparing Perioperative Chemotherapy and Surgery With Surgery Alone in Resectable Stage IIIA Non-Small-Cell Lung Cancer. Journal of National Cancer Institute, Vol. 86, No. 9, (May 1994), pp.673-680

Rusch, V.W., Rosenzweig, K., Venkatraman, E., Leon, L., Raben, A., Harrison, L., Bains, M.S., Downey, R.J., \& Ginsberg R.J. (2001). A phase II trial of surgical resection and adjuvant high-dose hemithoracic radiation for malignant pleural mesothelioma. Journal of Thoracic and Cardiovascular Surgery, Vol. 122, No. 4, (October 2011), pp. 788-795

Song W.A., Zhou N.K., Wang W., Chu X.Y., Liang C.Y., Tian X.D., Guo J.T., Liu X., Liu Y., Dai W.M. Survival benefit of neoadjuvant chemotherapy in non-small cell lung cancer: an updated meta-analysis of 13 randomized control trials. J Thorac Oncol. Vol..5, No 4: pp. 510-6.

Stewart, D.J., Martin-Ucar, A.E., Edwards, J.G., West, K., \& Waller, D.A. (2005). Extrapleural pneumonectomy for malignant pleural mesothelioma: the risks of induction chemotherapy, right-sided procedures and prolonged operations. European Journal of Cardio-thoracic Surgery, Vol. 27, No. 3, (March 2005), pp. 373-378 
Sugarbaker, D.J., Flores, R.M., Jaklitsch, M.T., Richards, W.J., Strauss, G.M., Corson, J.M., DeCAmp, M.M., Swanson, S.J., Bueno, R., Lukanich, J.M., Baldini, E.H., Mentzer, S.J. Resection margins, extrapleural nodal status, and cell type determine postoperative long-term survival in trimodality therapy of malignant pleural mesothelioma: results in 183 patients. (1999). Journal of Thoracic and Cardiovascular Surgery, Vol. 117, N0. 1, (January 1999), pp. 54-63

Treasure, T., Tan, C., Lang-Lazdunski, L., \& Waller, D. (2006). The MARS trial: mesothelioma and radical surgery. Interactive Cardiovascular and Thoracic Surgery, Vol. 5, No. 1, (January 2006), pp.58-59

Treasure, T., Waller, D., Tan, C., Entwisle, J., O’Brien, M., O’Byrne, K., Thomas, G., Snee, M., Spicer, J., Landau, D., Lang-Lazdunski, L., Bliss, J., Peckitt, C., Rogers, S., Marriage, E., Coombes, G., Webster-Smitt, M., \& Peto, J. (2009). The Mesothelioma and Radical Surgery Randomized Controlled Trial. The MARS feasibility study. Journal of Thoracic Oncology, Vol. 4, No. 10, (October 2009), pp. 1254-1258

Treasure, T., Lang-Lazdunski, L., Waller, D., Bliss, J.M., Tan, C., Entwisle, J., Snee, M., O’Brien, M., Thomas, G., Senan, S., O'Byrne, K., Kilburn, L.S., Spicer, J., Landau, D., Edwards, J., Coombes, G., Darlison, L., \& Peto, J. (2011). Extra-pleural pneumonectomy versus no extra-pleural pneumonectomy for patients with malignant pleural mesothelioma: clinical outcomes of the Mesothelioma and Radical Surgery (MARS) randomised feasibility study. Lancet Oncology, Vol. 12, No. 8, (August 2011), pp. 763-772

Van Meerbeeck, J.P., Gaafar, R., Manegold, C., Van Klaveren, R.J., Van Marck, E.A., Vincent, M., Legrand, C., Bottomley, A., Debruyne, C., \& Giaccone, G. (2005). Randomized phase III study of cisplatin with or without raltitrexed in patients with malignant pleural mesothelioma: an intergroup study of the European Organisation for Research and Treatment of Cancer Lung Cancer Group and the National Cancer Institute of Canada. Journal of Clinical Oncology, Vol. 23, No. 28, (October 2005), pp. 6881-6888

Van Schil, P.E., Bass, P., Gaafar, R., Maat, A.P., Van de Pol, M., Hasan, B., Klomp, H.M., Abdelrahman, A.M., Welch, J., \& van Meerbeeck, J.P. (2010). Trimodality therapy for malignant pleural mesothelioma: results from an EORTC phase II multicentre trial. European Respiratory Journal, Vol. 36, No. 6, (June 2010), pp. 1362- 1369

Vogelzang, N.J., Rusthoven, J.J., Symanoski, J., Denham, C., Kaukel, E., Ruffie, P., Gatzemeier, U., Boyer, M., Emri, S., Manegold, C., Niyikiza, C. \& Paoletti, P. (2003). Phase II Study of pemetrexed in combination with cisplatin versus cisplatin alone in patients with malignant pleural mesothelioma. Journal of Clinical Oncology, Vol. 21, No. 14, (July 2003), pp. 2636-2644

Weder, W., Kestenholz, P., Taverna, C., Bodis, S., Lardinois, D., Jerman, M., \& Stahel, R. (2004). Neoadjuvant chemotherapy followed by extrapleural pneumonectomy in malignant pleural mesothelioma. Journal of Clinical Oncology, Vol. 22, No. 17, (September 2004), pp. 3451-3457 
Weder, W., Stahel, R.A., Bernahrd, J., Bodis, S., Vogt, P., Ballabeni, P., Lardinois, D., Betticher, D., Schmid, R., Stupp, R., Ris, H.B., Jermann, M., Mingrone, W., Roth, A.D., \& Spiliopoulos, A. (2007). Multicenter trial of neo-adjuvant chemotherapy followed by extrapleural pneumonectomy in malignant pleural mesothelioma. Annals of Oncology, Vol. 18, No. 7, (July 2007), pp.1196-1202 